\title{
PENGATURAN PERANGKAT EXHAUST PADA RUANG MEROKOK MENGGUNAKAN WIRELESS SENSOR NETWORK
}

\author{
Abdul Rasyid, Mochammad Junus, Arinalhaq Fatachul, Binti Asfaki Ludiyah, Marina Annisa Fitri \\ Jurusan Teknik Elektro, Politeknik Negeri Malang \\ rasyid@polinema.ac.id
}

(Artikel diterima: Februari 2020, direvisi: April 2020, diterima untuk terbit: Juli 2020)

\begin{abstract}
Abstrak - Jumlah Perokok di Indonesia cukup besar, untuk Kesehatan bagi non perokok, sudah banyak disediakan ruang khusus untuk para perokok yang akan menikmati rokoknya dan ruangan yang tersedia banyak yang menggunakan kipas angin penghisap (Exhaust), dalam hal ini Exhaust yang disiapkan bersifat statis atau tetap, tentang besar penghisapannya. Untuk kenyamanan dan kesehatan para perokok perlu diatur, besar atau kecil hisapan dari kipas angin penghisap atau Exhaust ini, besar kecilnya hisapan berdasarkan kepadatan asap rokok dalam satuan PPM (Part Permillion) di ruangan khusus perokok tersebut dan kepadatan Asap Rokok ditentukan dengan menggunakan sensor Gas MQ-135 Air Quality. Penelitian ini bertujuan untuk merancang dan membuat alat kontrol untuk mengatur kecepatan hisap perangkat kipas penghisap atau Exhaust berdasarkan kepadatan polusi asap rokok dalam ruangan, sehingga membuat nyaman dan cukup menyehatkan bagi para perokok dalam ruangan tersebut. Selanjutnya hasil pengukuran kadar asap rokok dan besaran kecepatan perangkat Exhaust ditampilkan di ruangan merokok menggunakan display monitor, dan dengan XBee tx maupun rx secara wireless hasil pengaturan dapat diamati melalui Laptop atau PC.
\end{abstract}

Kata kunci: jumlah, kata, kunci, minimal, lima, kata.

\section{Pendahuluan}

Pada umumnya merokok merupakan kebiasaan orang yang sering dilakukan di area fasilitas umum sehingga mengganggu kenyamanan dan juga dapat membahayakan orang lain yang berada di tempat tersebut. Hal itu membuat pemerintah menetapkan peraturan untuk menyediakan ruangan tersendiri untuk para perokok berat (Peraturan Pemerintah Republik Indonesia Nomor 19 Tahun 2003). Untuk mengkondisikan udara agar tetap terjaga segar maka diperlukan exhaust yang nantinya akan mengatur sirkulasi udara di dalam ruangan. Selama ini untuk mengatur sirkulasi udaranya, exhaust bekerja dengan kontrol manual. Selain itu jika dilihat dari sisi pengelolaan gedung, terdapat pemborosan energi listrik karena exhaust diruang khusus merokok selalu menyala dan jika pun ada tombol on/off masih harus ditekan secara manual oleh bantuan manusia. Pada Penelitian ini, sistem pengaturan dalam mengontrol kecepatan exhaust dibuat secara otomatis yaitu dengan menggunakan deteksi asap rokok yang dideteksi dengan sensor asap MQ 135 untuk mengatur kecepatan exhaust pada ruang khusus merokok dan membuat udara diruang merokok disirkulasi dengan baik. Selain itu, untuk hal monitoring kondisi ruangan agar kondisi udaranya tetap stabil yaitu dengan menggunakan konsep wireless sensor network dengan modul utamanya prosesor Xbee keluaran Digi Internasional yang dapat mengolah data dan mentransmisikan secara wireless.

\section{A. Rumusan Masalah}

Berdasarkan latar belakang tersebut maka rumusan masalah yang didapat adalah sebagai berikut:

- Bagaimana mendeteksi asap rokok pada ruangan.

- Bagaimana mengendalikan kecepatan exhaust secara otomatis.

- Bagaimana memonitoring kondisi ruang merokok dengan konsep wireless.

\section{B. Tujuan Penelitian}

Tujuan penelitian adalah sebagai berikut:

- Merancang sistem yang berfungsi untuk mendeteksi asap dengan tampilan nilai ppm pada LCD.

- Merancang sistem yang bersifat realtime.

- Untuk mengetahui konsep monitoring kondisi ruangan agar udara tetap stabil

\section{Batasan Masalah}

Batasan masalah untuk penelitian ini adalah:

- Anouncer yang berupa lampu LED.

- Output hasil pengukuran ditampilkan pada LCD.

- Sample berupa asap rokok.

- Jarak pengiriman data untuk monitoring menggunakan xbee yaitu 10 meter

\section{Manfaat Penelitian} berikut:

Manfaat dari pembuatan aplikasi ini adalah sebagai

\section{- $\quad$ Bagi peneliti}

Mendapatkan wawasan dan pengetahuan tentang pembuatan sistem pengontrolan asap rokok pada ruangan.

- $\quad$ Bagi Politeknik Negeri Malang

Memberikan wawasan dan pengetahuan tentang pembuatan sistem pengontrolan asap rokok pada ruangan. 


\section{KaJian PUSTAKa}

\section{A. Peneliti Sebelumnya}

Pada penelitian yang di buat oleh Wahyu Surya, Gigih Prabowo, dan Indhana Sudiharto ini berjudul 'Pengontrolan Kecepatan Exausht Pada Ruang Merokok Berdasar Kendali Logika Fuzzy Berbasis Mikrokontroller AT Mega 16' [3],pengontrolan exhaust secaraotomatis bertujuan untuk mendapatkan kondisi udarayang stabil di dalam ruangan sehingga akanmendapatkan kondisi yang lebih nyaman denganmengidentifikasi kebutuhan udara dan intensitas asaprokok. Referensi suhu normal pada ruangan adalah270celcius sedangkan setting intensitas asap rokok oleh sensor adalah range antara 0,009 sampai0,060\% vol. Pengontrolan kecepatan exhaust dilakukan berdasarkan metode kendali logika fuzzy.Terdapat empat parameter yang dijadikan inputdalam fuzzy yaitu error dan delta error suhu sertaerror dan delta error asap rokok. Output pengontrolan yang didapatkan adalah saat suhu dan intensitas asap rokok terdeteksi maka putaran exhaust akan menyesuaikan dengan rule base fuzzy yang tersedia untuk mendapatkan kondisi ruangan yang kembali ke set point suhu $27^{\circ}$ dan intensitas asap rokok $0,009 \%$ vol.

Selain itu, pada penelitian yang dibuat oleh Ferdian Agil Denny Effendy yang berjudul "Kendali Kecepatan Kipas Pembuangan Pada Ruang Khusus Merokok Sebagai Pembersih Dan Pengatur Sirkulasi Udara Berbasis Mikrokontroller" dijelaskan bahwa system untuk mengatur kecepatan kipas pembuangan pada ruang khusus merokok secara otomatis dan mengatur sirkulasi udara diruangan tersebut dengan memberikan ionizer untuk membersihkan udara dengan ion negative. Pada system ini menggunakan mikrokontroller AVR ATMega 8535 sebagai pengendali.Sistem ini menggunakan sensor MQ-135 untuk mendeteksi asap rokok yang digunakan sebagai input untuk mikrokontroller, lalu diolah untuk dijadikan input pada blok pengaturan kecepatan kipas pembuangan dengan menggunakan trigger berupa sinyal PWM. Dari hasil penelitian, jika ditinjau dari segi kenyamanan, sistem yang telah dibuat ini memiliki respon waktu pembersihan lebih cepat menggunakan ionizer, sehinggga memberikan kenyamanan. Secara umum dapat disimpulkan bahwa dengan menggunakan system ini peningkatan efisiensi energi telah tercapai dengan tingkat penghematan daya mencapai 20-30\% dibandingkan dengan tanpa pengontrolan [4].

Pada proyek akhir yang pernah dibuat oleh Tania Fatmacory, dkk. dengan judul "Perancangan Dan Realisasi Filter Udara Untuk Asap Rokok Berbasiskan Mikrokontroler Atmega 8535". Pada proyek akhir ini telah dirancang sebuah prototype dari filter udara berbasiskan mikrokontroler ATMega 8535. Mikrokontroler mengatur integrasi antara sensor MQ135 sebagai pendeteksi asap rokok di udara dan kipas sebagai penghirup udara kotor agar masuk ke blok pembersih udara (blok filter). Pada blok filter, aliran udara bertemu dengan saringan kawat dan sinar ultraviolet (UV). Untuk menjaga agar aliran udara di dalam blok ini lancar, digunakan satu kipas lagi yang menarik udara keluar dari pembersih udara. Kipas yang kedua ini juga diaktifkan secara otomatis oleh mikrokontroler.

Perangkat filter udara ini dapat bekerja secara otomatis untuk membersihkan udara. Seluruh perangkat filter, kecuali bagian sensor dan blok ultraviolet, hanya aktif jika sensor mendeteksi asap rokok di udara. Udara yang keluar dari filter menjadi lebih bersih dan berdasarkan pengamatan terhadap output filter, konsentrasi asap rokok menjadi lebih berkurang.

\section{B. Tinjauan Teori}

\section{MQ-135 Air Quality}

MQ-135 Air Quality Sensor adalah sensor yang memonitor kualitas udara untuk mendeteksi gas amonia $\left(\mathrm{NH}_{3}\right)$, natrium-(di)oksida $\left(\mathrm{NO}_{x}\right)$, alkohol/ethanol $\left(\mathrm{C}_{2} \mathrm{H}_{5} \mathrm{OH}\right)$, benzena $\left(\mathrm{C}_{6} \mathrm{H}_{6}\right)$, karbondioksida $\left(\mathrm{CO}_{2}\right)$, gas belerang/sulfurhidroksida $\left(\mathrm{H}_{2} \mathrm{~S}\right)$ dan asap/gas-gas lainnya di udara. Sensor ini melaporkan hasil deteksi kualitas udara berupa perubahan nilai resistensi analog di pin keluarannya. Pin keluaran ini bisa disambungkan dengan pin ADC (analog-to-digital converter) di mikrokontroler/pin analog input Arduino Anda dengan menambahkan satu buah resistor saja (berfungsi sebagai pembagi tegangan/voltage divider).

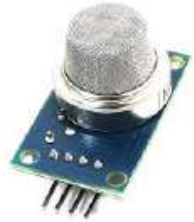

Gambar 2.1 MQ 135 Air Quality

Tabel 2.1 Spesifikasi MQ 135 Air Quality

\begin{tabular}{|c|c|c|}
\hline Parameter & Kondisi Teknis & Keterangan \\
\hline Circuit voltage & $5 \mathrm{~V} \pm 0,1$ & $\begin{array}{l}\text { AC atau } \\
\text { DC }\end{array}$ \\
\hline Heating voltage & $5 \mathrm{~V} \pm 0,1$ & $\begin{array}{l}\text { AC atau } \\
\text { DC }\end{array}$ \\
\hline Load resistance & Bisa menyesuaikan & \\
\hline $\begin{array}{l}\text { Heater } \\
\text { resistance }\end{array}$ & $33 \Omega \pm 5 \%$ & $\begin{array}{l}\text { Suhu } \\
\text { ruangan }\end{array}$ \\
\hline $\begin{array}{l}\text { Heating } \\
\text { consumption }\end{array}$ & Kurang dari $800 \mathrm{~mW}$ & \\
\hline $\begin{array}{l}\text { Jangkauan } \\
\text { pengukuran }\end{array}$ & $\begin{array}{l}10-300 \text { ppm amonia } \\
10-1000 \text { ppm bensol } \\
10-300 \text { alkohol }\end{array}$ & \\
\hline
\end{tabular}

\section{Asap Rokok}

Asap rokok mengandung ribuan bahan kimia beracun dan bahan-bahan yang dapat menimbulkan kanker (karsinogen). Bahan berbahaya dan racun dalam rokok tidak hanya mengakibatkan gangguan kesehatan pada orang yang merokok (perokok aktif), namun juga pada orang-orang disekitarnya yang tidak merokok (perokok pasif). Perokok pasif mempunyai resiko lebih tinggi untuk menderita kanker paruparu dan penyakit jantung.

Ada dua macam asap rokok yang mengganggu kesehatan, yaitu asap utama (main stream) dan asap sampingan (side stream). Asap utama (main stream) adalah asap yang dihisap oleh si perokok. Asap sampingan (side stream) adalah asap yang merupakan pembakaran dari ujung rokok yang kemudian menyebar ke udara. Asap sampingan memiliki konsentrasi yang lebih tinggi, karena tidak melalui proses penyaringan yang cukup, dengan demikian pengisap asap sampingan memiliki resiko yang lebih tinggi untuk menderita gangguan kesehatan akibat rokok (Basha, Adnil, 2004:12). Berikut Kadar dan Kategori Indeks Standar : 


\begin{tabular}{|c|c|}
\hline Kategori & Kadar (dalam ppm) \\
\hline Baik & $0-50 \mathrm{ppm}$ \\
Sedang & $51-100 \mathrm{ppm}$ \\
Tidak Sehat & $101-299 \mathrm{ppm}$ \\
Berbahaya & $<300 \mathrm{ppm}$ \\
\hline
\end{tabular}

Gambar 2.2 Tabel kadar dan kategori indeks standar, Sumber : ISPU (Indeks Standar Pencemaran Udara)

\section{Satuan Konsentrasi Asap Rokok}

Satuan yang dipakai untuk mengukur konsentrasi kandungan asap rokok yaitu PPM (Part perMillion). PPM bisa dalam volume (ppm volume) atau massa/berat (ppm mass/weight), jika diartikan kedalam bahasa Indonesia akan menjadi "Bagian per Sejuta Bagian" yang artinya adalah satuan konsentrasi yang menyatakan perbandingan bagain dalam satu juta bagian yang lain. Ppm adalah satuan konsentrasi yang dinyatakan dalam satuan $\mathrm{mg} / \mathrm{Kg}, 1 \mathrm{Kg}=$ $1.000 .000 \mathrm{mg}$. Untuk satuan yang sering dipergunakan dalam larutan adalah $\mathrm{mg} / \mathrm{L}$, dengan ketentuan pelarutnya adalah air sebab dengan densitas air $1 \mathrm{~g} / \mathrm{mL}$ maka 1 liter air memiliki masa $1 \mathrm{Kg}$. Jadi satuannya akan kembali ke mg/Kg.

\section{E. Arduino}

Arduino dikatakan sebagai sebuah platform dari physical computing yang bersifat open source. Pertama-tama perlu dipahami bahwa kata "platform" di sini adalah sebuah pilihan kata yang tepat. Arduino tidak hanya sekedar sebuah alat pengembangan, tetapi ia adalah kombinasi dari hardware, bahasa pemrograman dan Integrated Development Environment (IDE) yang canggih. IDE adalah sebuah software yang sangat berperan untuk menulis program, meng-compile menjadi kode biner dan meng-upload ke dalam memory microcontroller. Ada banyak projek dan alatalat dikembangkan oleh akademisi dan profesional dengan menggunakan Arduino, selain itu juga ada banyak modulmodul pendukung (sensor, tampilan, penggerak dan sebagainya) yang dibuat oleh pihak lain untuk bisa disambungkan dengan Arduino. Arduino berevolusi menjadi sebuah platform karena ia menjadi pilihan dan acuan bagi banyak praktisi.

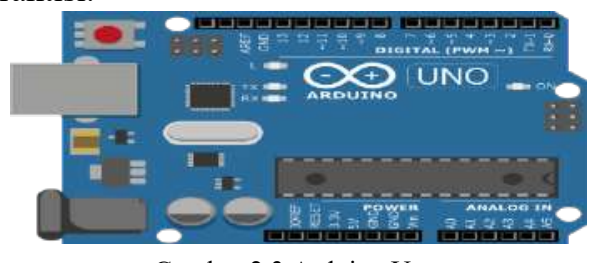

Gambar 2.3 Arduino Uno

Komponen utama di dalam papan Arduino adalah sebuah microcontroller 8 bit dengan merk ATmega yang dibuat oleh perusahaan Atmel Corporation. Berbagai papan Arduino menggunakan tipe ATmega yang berbeda-beda tergantung dari spesifikasinya, sebagai contoh Arduino Uno menggunakan ATmega328 sedangkan Arduino Mega 2560 yang lebih canggih menggunakan ATmega2560.

Untuk memberikan gambaran mengenai apa saja yang terdapat di dalam sebuah microcontroller, pada gambar berikut ini diperlihatkan contoh diagram blok sederhana dari microcontroller ATmega328 (dipakai pada Arduino Uno).

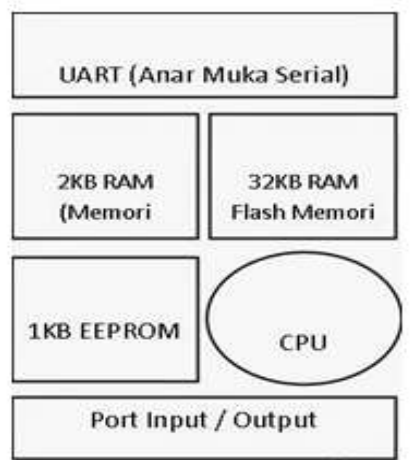

Gambar 2.4 Blok diagram microcontroller ATmega328
Sumber: Feri Djuandi. 2011

Blok diagram microcontroller dapat dijelaskan sebagai berikut:

1. Universal Asynchronous Receiver/Transmitter (UART) adalah antar muka yang digunakan untuk komunikasi serial seperti pada RS-232, RS-422 dan RS-485.

2. $2 \mathrm{~KB}$ RAM pada memory kerja bersifat volatile (hilang saat daya dimatikan), digunakan oleh variable-variabel di dalam program.

3. 32KB RAM flash memory bersifat non-volatile, digunakan untuk menyimpan program yang dimuat dari komputer. Selain program, flash memory juga menyimpan bootloader. Bootloader adalah program inisiasi yang ukurannya kecil, dijalankan oleh CPU saat daya dihidupkan. Setelah bootloader selesai dijalankan, berikutnya program di dalam RAM akan dieksekusi.

4. 1KB EEPROM bersifat non-volatile, digunakan untuk menyimpan data yang tidak boleh hilang saat daya dimatikan. Tidak digunakan pada papan Arduino.

5. Central Processing Unit (CPU), bagian dari microcontroller untuk menjalankan setiap instruksi dari program.

6. Port input/output, pin-pin untuk menerima data (input) digital atau analog, dan mengeluarkan data (output) digital atau analog.

\section{F. XBee}

Telemetri atau komunikasi data tanpa kabel (wireless) merupakan cara yang efektif untuk komunikasi jarak jauh tanpa harus terganggu dengan jalur kabel yang panjang. Modul telemetri pun beragam, ada yang menggunakan komunikasi serial (seperti XBee, YS-1020, TLP-RLP 434) dan SPI (RFM01-RFM02, RFM12). Modul telemetri juga menggunakan system modulasi yang berbeda seperti ASK, FSK, PSK, dsb. Contoh telemetri dengan SPI telah saya bahas pada tutorial RFM01-RFM02.

Kelebihan XBee:

- Memiliki transfer rate sekitar 250Kbps.

- Jarak/range kerja sekitar 76 meter.

Konsumsi daya rendah.

- $\quad$ Bekerja pada frekuensi 2,4GHz 
Berikut adalah konfigurasi pin-pin Xbee dan penjelasannya :

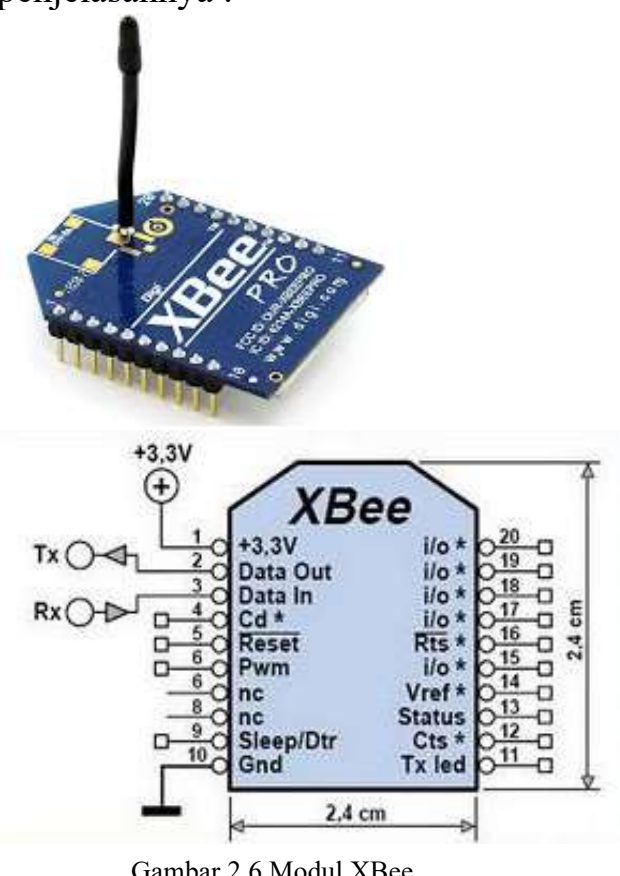

\section{G. Pengoperasian Xbee}

Modul XBee dihubungkan dengan host melalui level logika port serial asinkron. Melalui port serial ini, modul XBee dapat berkomunikasi dengan logika dan tegangan yang kompatibel dengan UART atau melalui level translator ke sembarang device serial, seperti RS-232/485/422 atau USB.

Device yang mempunyai UART interface dapat langsung dihubungkan secara langsung dengan pin-pin modul XBee.

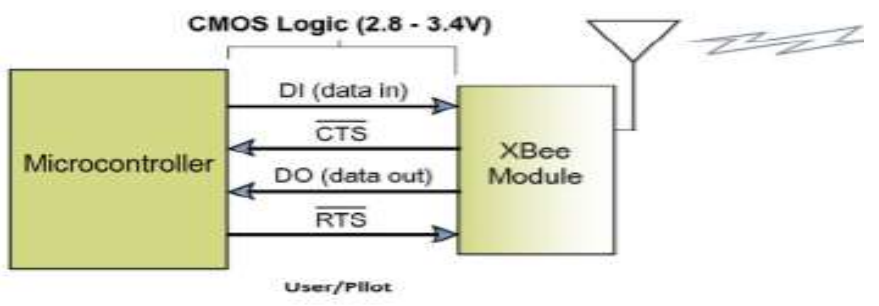

Gambar 2.7 Diagram Sistem Aliran Data pada Xbee

\section{Metodologi Penelitian}

\section{A. Tahapan Penelitian}

Dalam tahapan penelitian terdapat beberapa tahapan yang harus dilakukan yaitu sebagai berikut:

1. Pra penelitian: merupakan kegiatan sebelum melakukan penelitian meliputi identifikasi masalah, mencari jurnal yang menunjang dan studi literature secara mendalam:

a. Identifikasi masalah yaitu mencari sebuah masalah yang ada untuk diangkat dan menjadi bahan penelitian . b. Studi literatur yaitu mencari sumber-sumber kajian, jurnal, penelitian sebelumnya untuk menunjang penelitian yang dilakukan.

2. Penelitian: kegiatan saat melakukan penelitian meliputi pengumpulan data yang dibutuhkan untuk desain sistem dan merancang sistem.

a. Pengumpulan data dilakukan dengan mengambil data yang dibutuhkan untuk mengolah hasil gambar pada pengolahan citra.

- Data yang dibutuhkan adalah mengenai asap rokok.

- Pengumpulan data dilakukan dengan cara mencari refrensi pada paper mengenai asap rokok.

- Data setelah terkumpul nantinya akan digunakan sebagai dasar dalam pengaturan kecepatan Exhaust Fan.

b. Pengumpulan data mengenai perancangan pembuatan perangkat sistem deteksi asap rokok.

- Data yang dibutuhkan antara lain paper, buku, video tutorial dan datasheet perangkat yang digunakan antara lain, Mikrokontroller, XBee, Sensor MQ-135, Power Supply.

- Cara pengumpulan data dengan cara browsing, membaca dan mencari informasi pada forum.

- Data yang didapat nanti akan dipergunakan sebagai dasar perancangan dan pembuatan perangkat deteksi asap rokok.

c. Pengumpulan data yang diperoleh selanjutnya diteliti pada perangkat sistem yang dibuat pada sistem deteksi asap rokok.

- Data yang dibutuhkan adalah mengenai sistem deteksi asap rokok.

- Pengumpulan data dilakukan dengan cara mencari refrensi pada paper atau buku mengenai deteksi asap rokok.

- Data yang terkumpul nantinya digunakan sebagai dasar untuk menganalisa variable yang diteliti.

3. Pembuatan program pada bahasa pemrograman Arduino IDE untuk sensor MQ-135.

4. Simulasi alat dan pengujian : melakukan sismulasi pada alat dan program yang sudah dibuat dan dilakukan pengujian dari program yang berhasil.
a. Pengujian dari Sensor ke Arduino.
b. Pengujian dari $X B e e$ ke $P C$.
c. Pengujian dari XBee ke XBee.
d. Pengujian dari Mikrokontroller Arduino ke Exhaust Fan.

5. Pasca penelitian : merupakan kegiatan setelah penelitian yaitu menganalisa alat yang sudah berhasil dan membuat kesimpulan.
a. Pengujian keakuratan sensor.
b. Pengujian kualitas jaringan pada saat pengiriman data melalui PC pada ruang merokok sampai pada $\mathrm{PC}$ ruang monitoring melalui jaringan XBee.
c. Pengujian Fungsi Alat. 
Alur pelaksanaan tahapan penelitian dari proses awal sampai akhir dapat ditunjukan pada Gambar 3.1 berikut :

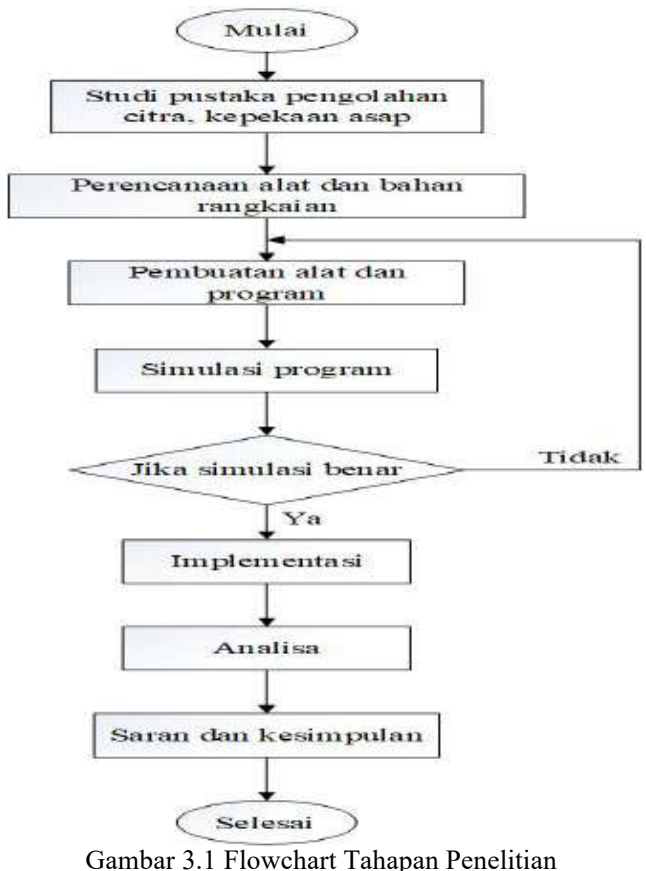

\subsection{Blok Diagram Sistem}

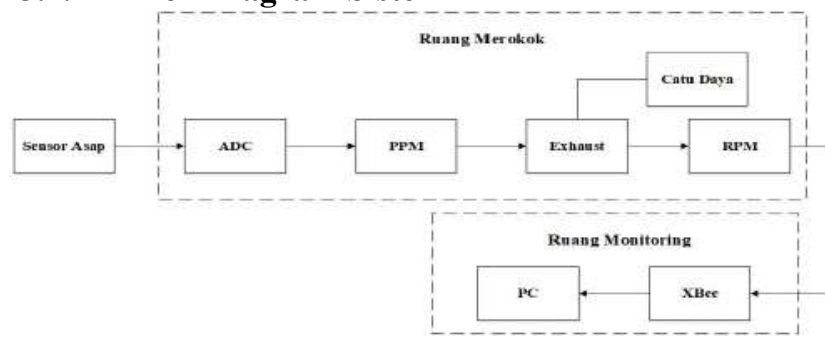

Gambar 3.2 Blok Diagram Sistem

Pada blok diagram sistem diatas, pada ruang merokok terdapat sensor MQ-135 yang merupakan input Arduino Uno melalui PIN A0 dimana Arduino Uno akan mengolah nilai ppm asap sebagai output. Nilai output digunakan untuk mengatur nyala warna merah,kuning dan hijau pada led bunyi buzzer serta untuk mengatur kecepatan exhaust dengan nilai RPM.

Pengiriman data pada sitem ini diawali oleh sensor. Sensor akan bekerja untuk membaca nilai ppm asap. Hasil data tersebut akan dikirim ke ruang monitoring oleh XBee transmitter dan diterima oleh XBee receiver yang akan ditampilkan pada PC.
B. Flowchart

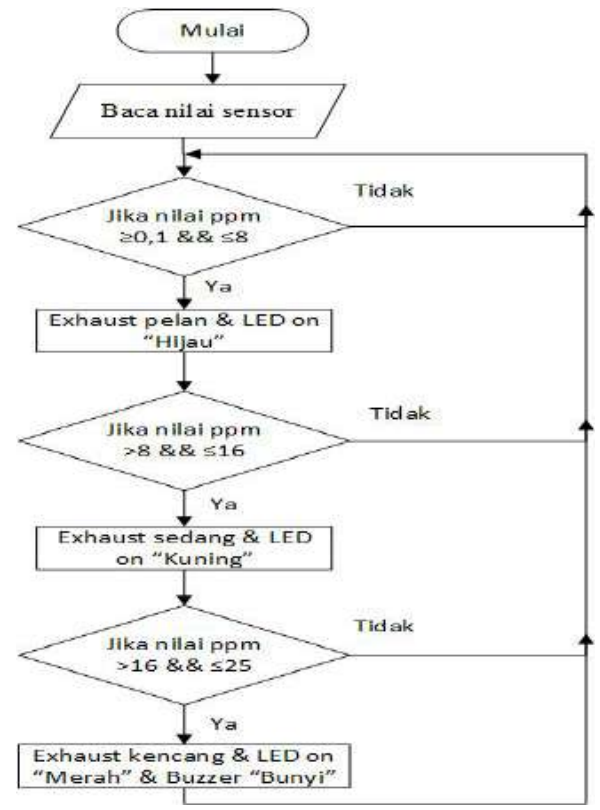

Gambar 3.3 Flowchart Algoritma

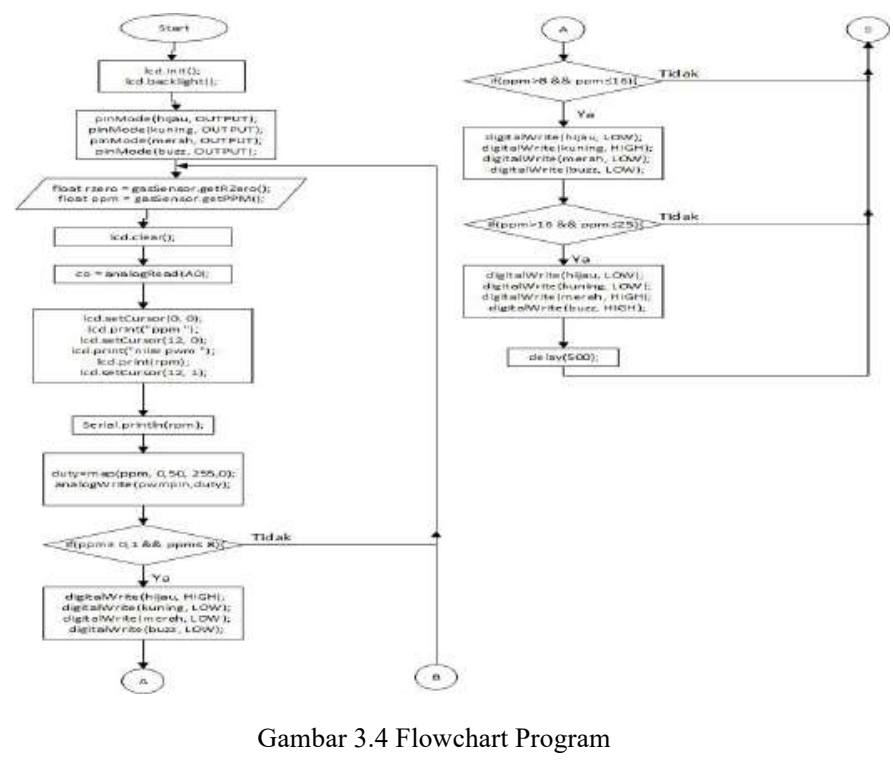

\section{Pengujian Dan Pembahasan}

Dari hasil perencanaan dan pembuatan alat pada bab 3 untuk mengetahui sistem yang telah dibuat sesuai dengan fungsi yang direncanakan, dilakukan pengujian terhadap sistem yang telah dibuat baik secara keseluruhan maupun subsistemnya. Pengujian dilakukan untuk mengetahui ketepatan dan kekurangan dari alat yang telah dibuat. Berikut ini merupakan penjelasan mengenai prosedur pengujian yang dilakukan.

\section{A. Pengujian Hardware}

Pengujian ini bertujuan untuk memperoleh nilai settingan input MQ 135 pada program Arduino IDE. Pengujian ini dilakukan ketika konsenstrasi asap (ppm) pada rentang nilai 2,5 ppm sampai $25 \mathrm{ppm}$ dengan selisih $2,5 \mathrm{ppm}$.

Peralatan yang digunakan pada pengujian sensor MQ 135 adalah sebagai berikut:

- Arduino Uno

- $\quad$ Sensor MQ 135 
- $\quad$ LED

- Buzzer

\section{B. Prosedur Pengujian}

Prosedur pengujian pada sensor MQ 135 adalah sebagai berikut :

- $\quad$ Rangkai Sensor MQ 135

- Hubungkan dengan Arduino Uno pada port A0.

- Hubungkan LED pada pin 10 untuk LED merah, pin 11 untuk LED kuning dan pin 12 untuk LED hijau pada Arduino Uno.

- Hubungkan buzzer pada pin 13 pada Arduino Uno.

- Masukkan program

- Catat hasil

\section{Hasil Pengujian}

Tujuan pada tahap ini adalah mengetahui nilai ADC pada sensor MQ 135 pada setiap kenaikan konsentrasi asap sebesar 2,5 ppm.

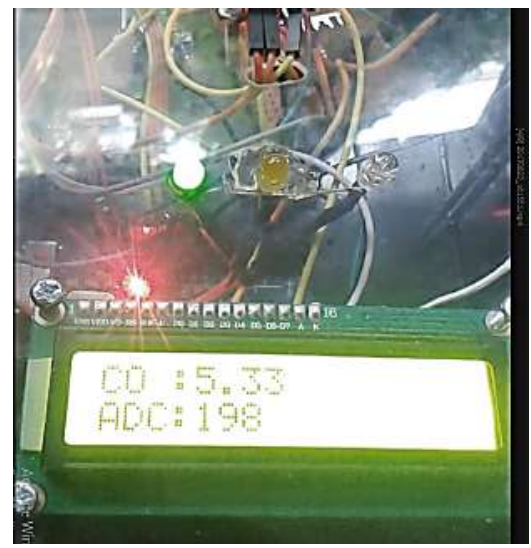

Gambar 4.1 Hasil Ketika Nilai Konsentrasi Asap 5 ppm, Nilai ADC 198 Dan Nyala LED Indikator Hijau

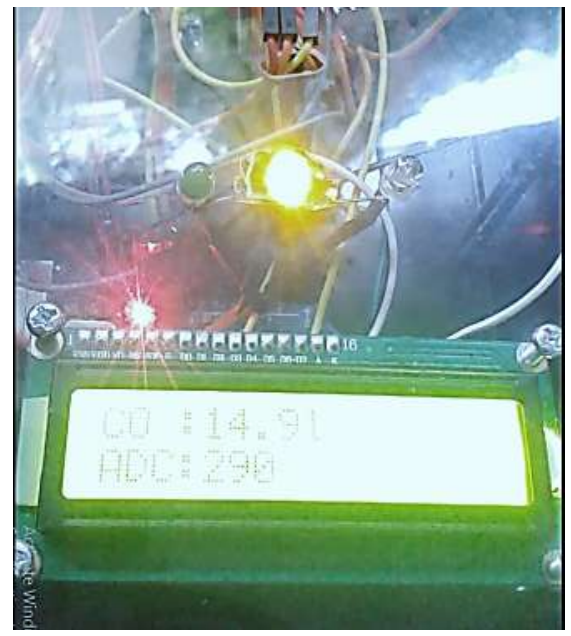

Gambar 4.2 Hasil Ketika Nilai Konsentrasi Asap 15 ppm, Nilai ADC 290 Dan Nyala LED Indikator Kuning

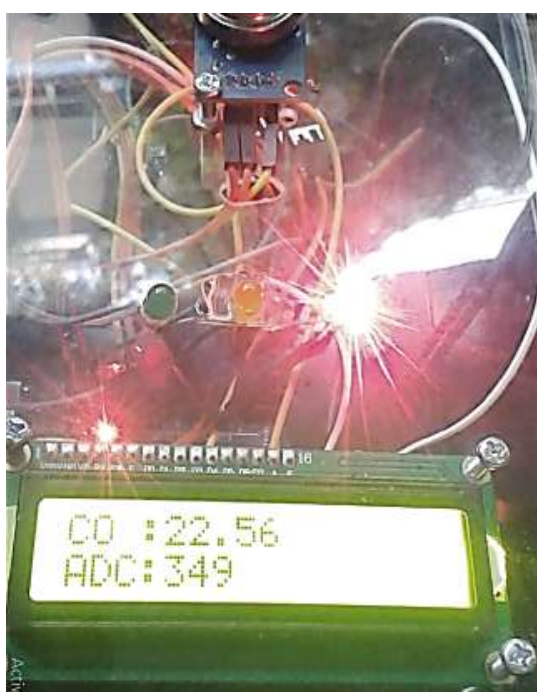

Gambar 4.3 Hasil Ketika Nilai Konsentrasi Asap 22,5 ppm, Nilai ADC 349 Dan Nyala LED Indikator Merah

Tabel 4.1 Pengujian Sensor MQ 135

\begin{tabular}{|c|c|c|c|}
\hline $\begin{array}{c}\text { Konsentrasi } \\
\text { Asap (ppm) }\end{array}$ & $\begin{array}{c}\text { Nilai } \\
\text { ADC }\end{array}$ & LED & Buzzer \\
\hline 2,5 & 159 & Hijau & Off \\
\hline 5 & 198 & Hijau & Off \\
\hline 7,5 & 223 & Hijau & Off \\
\hline 10 & 267 & Kuning & Off \\
\hline 12,5 & 277 & Kuning & Off \\
\hline 15 & 290 & Kuning & Off \\
\hline 17,5 & 319 & Merah & On \\
\hline 20 & 332 & Merah & On \\
\hline 22,5 & 349 & Merah & On \\
\hline 25 & 352 & Merah & On \\
\hline
\end{tabular}

\section{Pengujian Kecepatan Exhaust}

Pengujian ini bertujuan untuk membandingkan nilai kecepatan yang diatur Arduino sesuai dengan nilai konsentrasi asap dan nilai kecepatan exhaust yang diukur dengan menggunakan alat ukur kecepatan Digital Tachometer.

\section{Peralatan yang Digunakan}

Peralatan yang digunakan pada pengujian kecepatan Exhaust adalah sebagai berikut:

- $\quad$ Arduino Uno

- $\quad$ Sensor MQ 135

- Sensor Photodioda

- Exhaust Fan DC 12V

- $\quad$ Alat ukur Digital Tachometer

- Power Supply DC 12V

\section{Prosedur Pengujian}

Prosedur pengujian kecepatan Exhaust adalah sebagai berikut :

- Rangkai sensor MQ 135 dan sensor Photodioda

- Hubungkan sensor MQ 135 pada port A1 Arduino Uno

- Hubungkan sensor Photodioda pada Vcc, ground dan port PWM 4 pada Arduino Uno

- Masukkan program

- Bandingkan nilai yang terukur pada Tachometer dengan nilai yang terukur oleh sensor kecepatan 


\section{- Catat hasil}

\section{Hasil Pengujian}

Tujuan pada tahap ini yaitu mengetahui nilai kecepatan kipas yang didapat dari sensor Arduino dan nilai kecepatan kipas dari Tachometer (rpm).
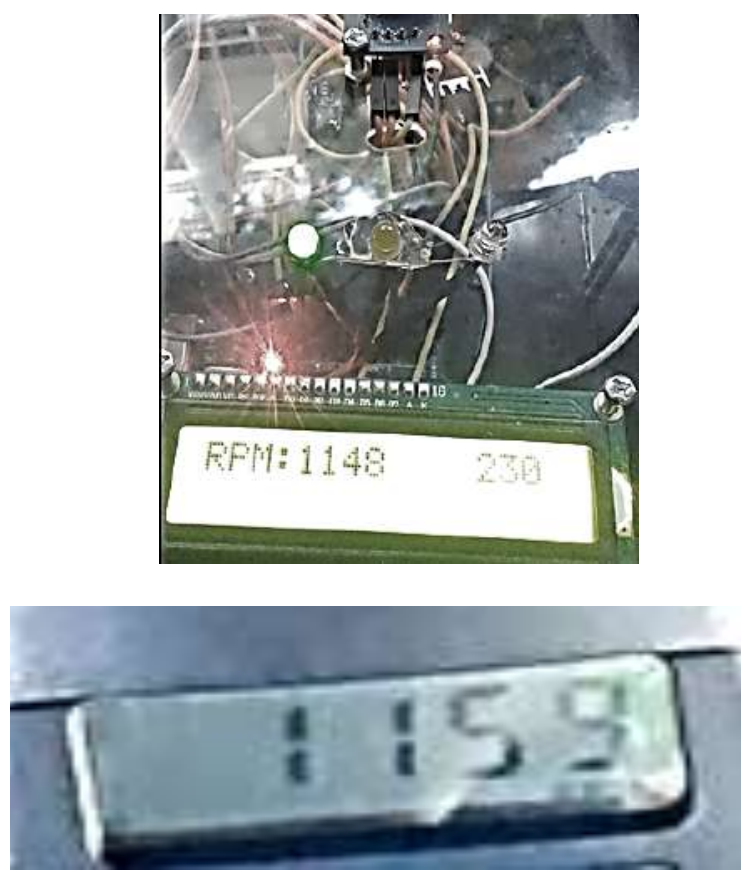

Gambar 4.4 Hasil Uji Kecepatan Kipas Kecil
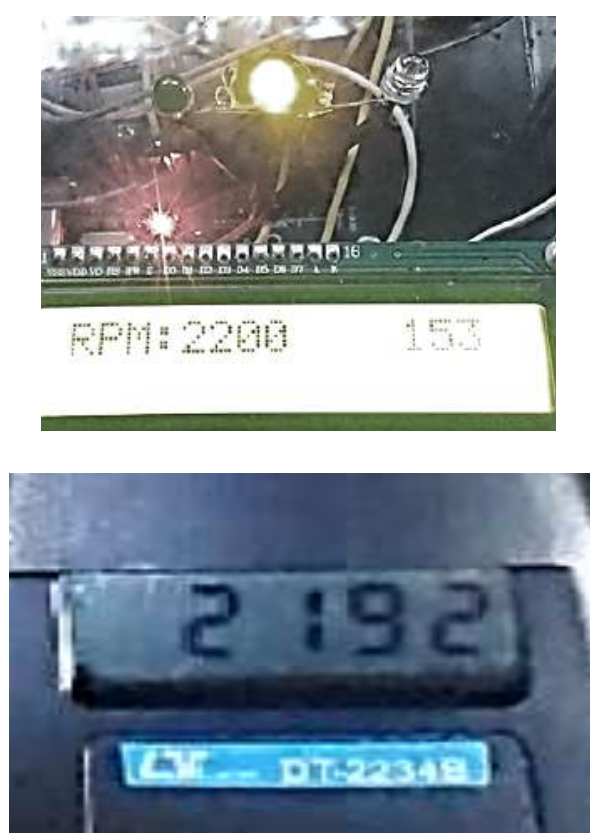

Gambar 4.5 Hasil Uji Kecepatan Kipas Sedang

\begin{tabular}{|c|c|c|c|c|c|}
\hline No. & \multicolumn{2}{|c|}{ PWM } & $\begin{array}{c}\text { Kecepatan } \\
\text { Kipas } \\
\text { Tachometer } \\
\text { (rpm) }\end{array}$ & $\begin{array}{c}\text { Kecepatan } \\
\text { Sensor } \\
\text { Photodioda } \\
\text { (rpm) }\end{array}$ & Error (\%) \\
\hline 1. & $100 \%$ & 255 & 0 & 0 & $0 \%$ \\
\hline 2. & $90 \%$ & 230 & 1159 & 1148 & $0,92 \%$ \\
\hline 3. & $80 \%$ & 204 & 1988 & 1923 & $3,38 \%$ \\
\hline 4. & $70 \%$ & 179 & 2018 & 2068 & $2,41 \%$ \\
\hline 5. & $60 \%$ & 153 & 2192 & 2200 & $0,36 \%$ \\
\hline 6. & $50 \%$ & 128 & 2293 & 2376 & $3,62 \%$ \\
\hline 7. & $40 \%$ & 102 & 2452 & 2506 & $2,20 \%$ \\
\hline 8. & $30 \%$ & 77 & 2692 & 2776 & $3,62 \%$ \\
\hline 9. & $20 \%$ & 51 & 3036 & 3090 & $1,75 \%$ \\
\hline 10. & $10 \%$ & 26 & 3175 & 3168 & $0,22 \%$ \\
\hline 11. & $0 \%$ & 0 & 3291 & 3300 & $0,27 \%$ \\
\hline
\end{tabular}

E. Pengujian Monitoring Kondisi Ruang Merokok Dengan Konsep Wireless

Dalam pengujian ini materi yang diuji yaitu kemampuan Xbee pro dalam berkomunikasi dengan jarak 1 meter sampai 10 meter. Pada pengujian ini alat dan bahan yang digunakan meliputi:

\section{Peralatan yang digunakan}

Peralatan yang digunakan pada pengujian monitoring kondisi ruang merokok adalah sebagai berikut:

- Arduino Uno

- $\quad$ Sensor MQ 135

- Sensor Photodioda

- Exhaust Fan DC 12V

- XBee Transmitter dan XBee Receiver

- $\quad$ Power Supply DC 12V

\section{Prosedur Pengujian}

Prosedur pengujian monitoring kondisi ruang merokok adalah sebagai berikut:

- Rangkai sensor MQ 135, sensor Photodioda dan XBee transmitter serta XBee receiver

- Hubungkan sensor MQ 135 pada port A1 Arduino Uno

- Hubungkan sensor Photodioda pada Vcc, ground dan port PWM 4 pada Arduino Uno

- Hubungkan XBee transmitter pada port Tx dan Rx di Arduino Uno

- Masukkan program

- Rangkai sensor MQ 135 dan sensor Photodioda

- Hubungkan sensor MQ 135 pada port A1 Arduino Uno

- Hubungkan sensor Photodioda pada Vcc, ground dan port PWM 4 pada Arduino Uno

- Masukkan program

- Catat hasil

\section{Hasil Pengujian}

Tujuan pada tahap ini yaitu mengetahui nilai kecepatan Exhaust yang didapat dari sensor Arduino (rpm) yang dikirim ke ruang monitoring melalui komunikasi XBee.

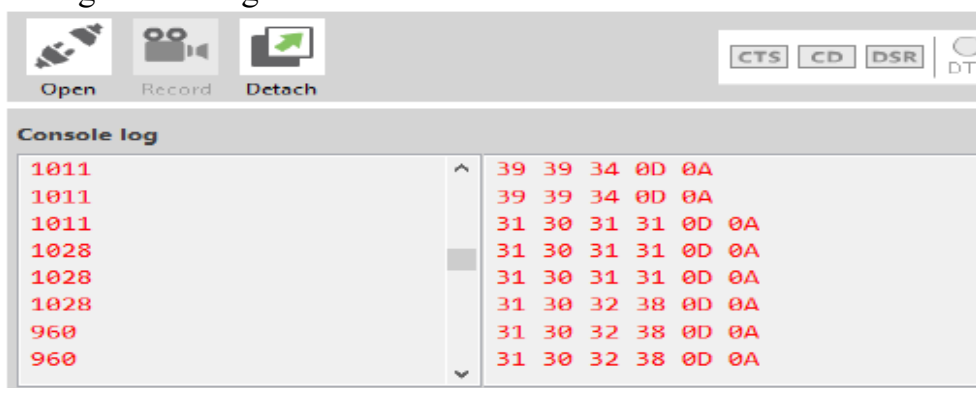


Gambar 4.7 Hasil Pengiriman Nilai Kecepatan Exhaust Ke Ruang Monitoring Melalui Software XCTU

Tabel 4.3 Pengujian Jarak Pengiriman Data Menggunakan Xbee

\begin{tabular}{|c|c|c|c|}
\hline No. & Jarak & Ada Halangan & Tanpa Halangan \\
\hline 1. & 1 meter & Berhasil & Berhasil \\
\hline 2. & 2 meter & Berhasil & Berhasil \\
\hline 3. & 3 meter & Berhasil & Berhasil \\
\hline 4. & 4 meter & Berhasil & Berhasil \\
\hline 5. & 5 meter & Berhasil & Berhasil \\
\hline 6. & 6 meter & Berhasil & Berhasil \\
\hline 7. & 7 meter & Berhasil & Berhasil \\
\hline 8. & 8 meter & Berhasil & Berhasil \\
\hline 9. & 9 meter & Berhasil & Berhasil \\
\hline 10. & 10 meter & Berhasil & Berhasil \\
\hline
\end{tabular}

\section{F. Pembahasan}

Pengontrolan kecepatan Exhaust dengan menggunakan deteksi asap rokok dikontrol oleh Arduino Uno. Sistem ini dimulai ketika sensor asap MQ-135 membaca konsentrasi asap (ppm). Nilai hasil pembacaan ini akan mengontrol kecepatan Exhaust. Jika konsentrasi asap (ppm) menunjukkan nilai ADC $<250$ maka kecepatan Exhaust kecil dengan nilai rpm dibawah $2000 \mathrm{rpm}$ dengan indikator nyala LED hijau, kemudian jika nilai konsentrasi asap menunjukkan nilai ADC $>250$ maka kecepatan Exhaust sedang dengan nilai rpm lebih dari 2000 rpm dengan indikator nyala LED kuning.

Selanjutnya , apabila nilai konsentrasi asap menunjukkan nilai ADC>300 maka kecepatan Exhaust keras dengan nilai rpm lebih dari $3000 \mathrm{rpm}$ dengan indikator nyala LED merah dan buzzer berbunyi yang menandakan asap sudah dalam kadar berbahaya untuk dihirup.

\section{KESIMPULAN}

- Kecepatan Exhaust bisa dikendalikan scara otomatis berdasarkan kepekatan asap rokok

- Informasi tentang nilai kepekatan dalam PPM dapat diperoleh outputnya setiap saat

- Hasil data yang diperoleh bisa dikirimkan menggunakan Xbee Pro maksimal pada jarak 10 meter

\section{DAfTar Pustaka}

[1] Putra, Prabowo, Sudiharto. Pengontrolan Kecepatan Exhaust Pada Ruang Merokok Berdasar Kendali Logika Fuzzy Berbasis Mikrokontroller AT Mega 16.Effendy,

[2] FerdianAgil Denny. Kendali Kecepatan Kipas Pembuangan Pada Ruang Khusus Merokok Sebagai Pembersih Dan Pengatur Sirkulasi Udara Berbasis Mikrokontroller. Bandung: Universitas Telkom.
[3] Tania, Sarwoko, Sugondo. 2012. Perancangan Dan Realisasi Filter Udar Untuk Asap Rokok Berbasiskan Mikrokontroler Atmega 8535.

[4] Anonim. Exhaust Fan. Diakses tanggal 17 Mei 2017, dari http://www.lamudi.co.id/journal/pengertianexhaust-fan-dan-cara-memilihnya/

[5] Anonim. Arduino. Diakses tanggal 3 Juni 2017, dari https://ariefeeiiggeennblog.wordpress.com/2014/0 2/07/pengertian-fungsi-dan-kegunaan-arduino/

[6] Anonim. Ruang Merokok. Diakses tanggal 17 Mei 2017, dari https://udararuang.wordpress.com/

[7] Anonim. Ruang Merokok. Diakses tanggal 10 Juli 2017, dari http://www.smokesolution.id/fitur-ruang-merokok/

[8] Anonim. PWM. Diakses tanggal 14 Juli 2017, dari https://globalenergizer.wordpress.com/2014/06/06/ pulse-width-modulation-pwm/ 